\title{
Costodorsalis - an Additional Slip of Pectoralis Major Muscle - a Case Report
}

\author{
Costodorsal - un Fascículo Adicional del Músculo Pectoral Mayor - Reporte de un Caso
}

Surekha D. Shetty; Satheesha Nayak B.; Naveen Kumar; S. N. Somayaji \& Mohandas Rao K. G.

SHETTY, S. D.; NAYAK, B. S.; KUMAR, N.; SOMAYAJI, S. N. \& RAO, K. G. M. Costodorsalis - an additional slip of pectoralis major muscle - a case report. Int. J. Morphol., 29(2):409-411, 2011.

SUMMARY: Occurrence of variant muscular slips from pectoralis major muscle is rare. In this report, we present a rare case of aberrant muscular slip associated with the pectoralis major muscle which we call costodorsalis. This muscular slip originated from the 6th rib near the costochondral junction and ran along the lower border of pectoralis major muscle. It crossed the axilla from medial to lateral side and merged with the latissimus dorsi muscle. This type of origin and insertion is unique and has not been reported earlier. The knowledge of this muscle variation may be of special importance to the anesthesiologists, physiotherapists and plastic surgeons.

KEY WORDS: Pectoralis major muscle; Latissimus dorsi muscle; Axilla; Variant muscular slip.

\section{INTRODUCTION}

The pectoralis major muscle takes its origin from the clavicle, sternum, 2nd to 6th ribs and the respective costal cartilages and the aponeurosis of the external oblique muscle of the abdomen. It is inserted to the lateral lip of the intertubercular sulcus of the humerus. It is supplied by the medial and lateral pectoral nerves. The muscle forms the anterior wall of the axilla and helps in adduction, flexion and medial rotation of the arm at the shoulder joint. The variants of pectoralis major muscle usually do not cause any symptoms but are of academic interest. They may present as a surgical problem, if they cause any symptoms. The chondro-epitrochlearis, costo-epitrochlearis or costohumeralis are some of the rare muscular variations that may arise from pectoralis major muscle crossing the axilla and inserting to the medial inter muscular septum or medial epichondyles of the humerus. In the present case, we found a variable muscular slip which is a very rare muscular anomaly of the pectoral region.

\section{CASE REPORT}

During the routine dissection classes for the medical undergraduate students at the Melaka Manipal Medical College (Manipal Campus), we observed a variation in the right upper limb of a 40-45 year old male cadaver. The skin, superficial and deep fascia were removed to expose the pectoral region, axilla and arm. The pectoralis muscle and its variant muscle slip were cleaned and photographed. The variant slip arose from the outer surface of the $6^{\text {th }}$ costal cartilage (Fig. 1). This slip ran parallel to the lower border o pectoralis major muscle and crossed the axilla and merged

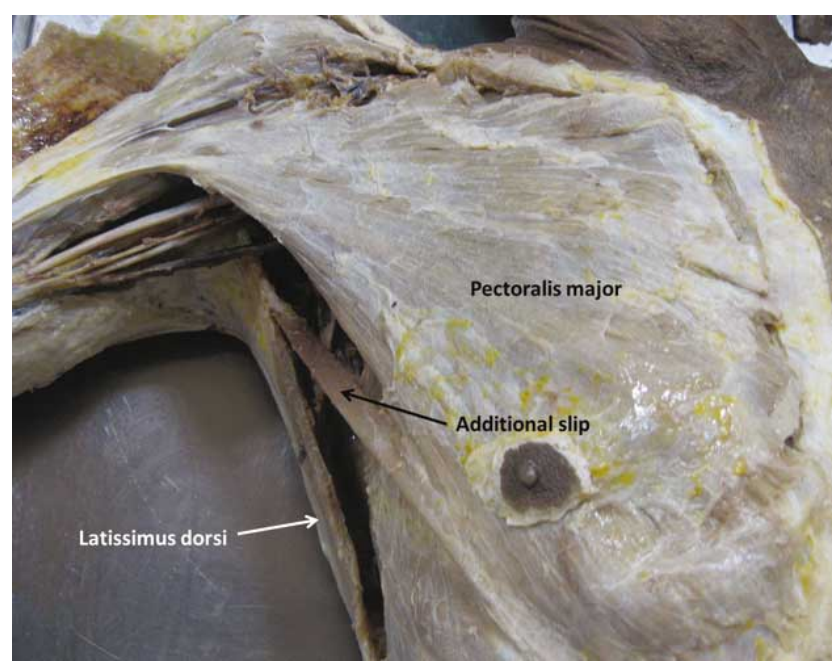

Fig. 1. Dissection of the pectoral region and axilla showing the additional slip associated with the pectoralis major muscle. 
with the aponeurosis of the latissimus dorsi to have same insertion as the latter (Fig. 2). It had the same innervation as the pectoralis major muscle. The variation noted was unilateral and there was no evidence of any other anomaly or pathology in the body.

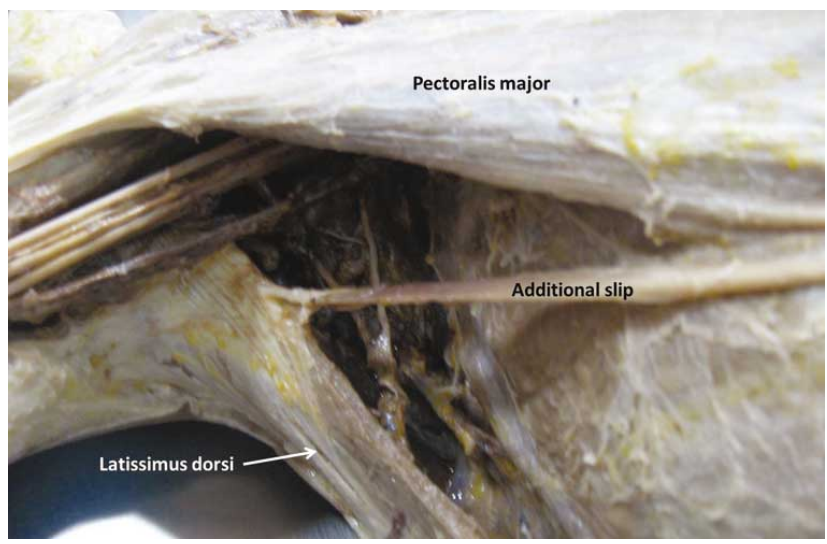

Fig. 2. Dissection of the axilla (inferior view) showing the additional muscle slip.

\section{DISCUSSION}

Many muscular variations in relation to the pectoralis major have been reported before, but it remains yet important to continue describing the rare variations due to their clinical implications. These variations are important in defining the anatomical features in relation to the clinical diagnosis and surgical procedures. The pectoralis major muscle may be looked upon as composed of four portions - a clavicular, a sternal, a costal and an abdominal, the last being the portion that arises from the aponeurosis of the external oblique. These parts vary in the extent of their attachments and in the degree of separation that they present. The abdominal portion may extend to the umbilicus. On the sternum the muscles of the two sides may decussate across the middle line. The sternocostal portions of the muscle may be deficient or missing the clavicular, but in rare cases the entire muscle may be absent. The clavicular portion of the muscle may be fused with the deltoid while the sternocostal portion may extend laterally to the latissimus dorsi. Rarely a slip may run from the pectoralis major to the biceps, the pectoralis minor, coracoid process, joint capsule or brachial fascia (Anson, 1966). Rao et al. (2009) have reported a rare costohumeralis muscle. It is an accessory slip of pectoralis major originating from the sixth rib near costochondral junction and running along the lower border of the pectoralis major muscle and getting inserted onto the medial epicondyle of the humerus. Chiba et al. (1983) have reported the presence of a muscle called chondro-epitrochlearis associated with axillary arch muscle in 7 to $13 \%$ of the population. Jaijesh (2005) reported the presence of unilateral chondro-epitrochlearis muscle with absence of normal twisted insertion of the pectoralis major muscle. Samuel \& Vollala (2008) also reported such a muscle and the blood and nerve supply to this variant muscle. The arterial supply to the chondro-epitrochlearis muscle was from the lateral thoracic artery and the nerve supply was through a branch of the medial pectoral nerve.

Loukas et al. (2005) presented a rare case of an accessory muscular slip originating from the pectoralis major and inserting to the medial epicondyle of the humerus and medial brachial intermuscular septum. They proposed a new nomenclature of this variant slip thoraco-epicondylaris. Lama et al. (2010) reported the presence of chondro humeralis and axillary arch of Langer; a rare combination of variant muscles with unique insertion. Bilateral epitrochlearis muscle associated with the bilateral absence of the axillary arch and absence of the normal twisted insertion of pectoralis major muscle has been reported by Flaherty et al. (1999). Presence of a pectoralis tertius muscle was reported by del Sol \& Vásquez (2009).

In the present case, we found a variable muscular slip which can be called 'costodorsalis' since it was arising from the rib and merging with the latissimus dorsi. Its unique insertion pattern has not been reported earlier. This anomalous slip crossed the base of axilla from medial to lateral side. It might surprise the surgeons doing any surgery of the axilla. The anomaly is of specific importance because of its potential to cause cosmetic defects and to restrict abduction of the arm. Thus, it may be of particular interest to surgeons, physiotherapists and plastic surgeons.

SHETTY, S. D.; NAYAK, B. S.; KUMAR, N.; SOMAYAJI, S. N. \& RAO, K. G. M. Costodorsal - un fasículo adicional del músculo pectoral mayor - reporte de un caso. Int. J. Morphol., 29(2):409-411, 2011.

RESUMEN: Es poco frecuente la aparición de variaciones de un fascículo muscular desde el músculo pectoral mayor . En este trabajo, presentamos el caso de un fascículo muscular aberrante asociado con el músculo pectoral mayor que denominamos costodorsal. Este fascículo muscular se originó en la $6^{\mathrm{a}}$ costilla cerca de la unión costocondral y corrió a lo largo del margen inferior del músculo pectoral mayor. Cruzó la axila de medial a lateral y se fusionó con el músculo latísimo del dorso. Este tipo de origen y la inserción es único y no se ha informado anteriormente. El conocimiento de esta variación muscular puede ser de especial importancia para los anestesistas, fisioterapeutas y cirujanos plásticos.

PALABRAS CLAVE: Músculo pectoral mayor; Músculo dorsal ancho; Axila; Fascículo muscular variante. 


\section{REFERENCES}

Anson, B. J. Morris' Human Anatomy. $12^{\text {th }}$ Ed. New York, McGraw-Hill, 1966. pp.478-9.

Chiba, S.; Suzuki, T. \& Kasai, T. A rare anomaly of the pectoralis major--the chondroepitrochlearis. Okajimas Folia Anat. Jpn., 60(2-3):175-85, 1983.

Del Sol, M. \& Vásquez, B. Anatomical and clinical considerations of the pectoralis tertius muscle in man. Int. J. Morphol., 27(3):715-8, 2009.

Flaherty, G.; O'Neill, M. N. \& Folan-Curran, J. Case report: bilateral occurrence of a chondroepitrochlearis muscle. J. Anat., 194(2):313-5, 1999.

Jaijesh, P. Unilateral appearance of a chondro-epitrochlearis muscle-a case report. Indian J. Plast. Surg., 38(2):1646, 2005.

Loukas, M.; Louis, R. G. Jr. \& Kwiatkowska, M. Chondroepitrochlearis muscle, a case report and a suggested revision of the current nomenclature. Surg. Radiol. Anat., 27(4):354-6, 2005.

Lama, P.; Potu, B. K. \& Bhat, K. M. Chondrohumeralis and axillary arch of Langer: a rare combination of variant muscles with unique insertion. Rom. J. Morphol. Embryol., 51(2):395-7, 2010.

Rao, T. R.; Shetty, P. \& Rao, S. Additional slip of pectoralis major muscle - the costohumeralis. Int. J. Anat. Variations, 2:35-7, 2009.

Samuel, V. P. \& Vollala, V. R. Unusual pectoralis major muscle: the chondroepitrochlearis. Anat. Sci. Int., 83(4):277-9, 2008.

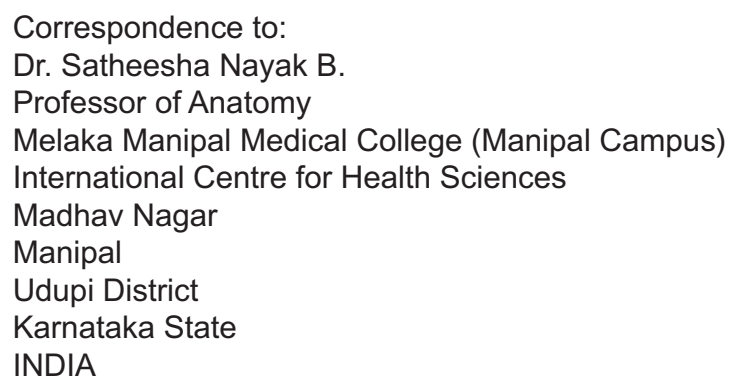

Telephone: +91 8202922519

Fax: +91 8202571905

Email: nayaksathish@yahoo.com

Received: 15-09-2010

Accepted: 22-03-2011 